\title{
Right place, right time
}

Eric B. Howell, MD, and Nahush A. Mokadam, MD

From the Division of Cardiothoracic Surgery, University of Washington, Seattle, Wash.

Disclosures: Dr Mokadam is a consultant and investigator for Medtronic, Abbott, and Syncardia. Dr Howell has nothing to disclose with regard to commercial support.

Received for publication May 4, 2018; revisions received May 4, 2018; accepted for publication May 7, 2018; available ahead of print June 19, 2018.

Address for reprints: Nahush A. Mokadam, MD, FACC, FACS, Division of Cardiothoracic Surgery, University of Washington, 1959 NE Pacific St, Box 356310, Seattle, WA 98195 (E-mail: mokadamn@uw.edu).

J Thorac Cardiovasc Surg 2018;156:1892-3

$0022-5223 / \$ 36.00$

Copyright (C) 2018 by The American Association for Thoracic Surgery

https://doi.org/10.1016/j.jtcvs.2018.05.019

Approximately 3500 years ago, the Egyptian dignitary Nebiri served as chief of stables under Thutmoses III, a pharaoh from the 18th Dynasty of ancient Egypt. ${ }^{1}$ Although little is known about the daily life of the hallowed horse whisperer, the discovery of his embalmed remains in the Valley of the Queens in Luxor and their more modern forensic analysis has provided the medical world with a unique and thought-provoking discovery: The earliest identified case of acute chronic decompensated heart failure. ${ }^{1}$ Although much has been learned with regard to heart failure and its management since the age of the ancient pharaohs, a multitude of questions still remain about how to effectively manage the physiology and pathophysiology of the body's most dynamic organ. In the current era of heart failure therapy, an evolving pharmacopeia and the development of both temporary and long-term mechanical circulatory support devices have provided renewed optimism for left heart support options; however, much less focus has been placed on the management of right heart (ie, right ventricle $[R V]$ ) dysfunction - a reality that is most likely due to a relative underappreciation for the importance of RV hemodynamic parameters and their associated effects on left heart optimization. $^{2}$

Bhama and colleagues ${ }^{3}$ provide a single-center, retrospective review of a prospectively collected dataset focusing on the use of temporary RV assist devices (RVADs) as a bridge to recovery or further intervention in patients who experienced acute RV failure. Patients who underwent RVAD placement for acute RV dysfunction were reviewed and divided into cohorts based on timing of RVAD initiation and indication for operation: postplacement of left ventricular assist device, posttransplant, and postcardiotomy. Overall, successful device wean occurred in $78 \%$ of patients. Failure to wean from RVAD support occurred most commonly in postcardiotomy patients who tended to be older and exhibited a higher prevalence of ischemic heart disease. Three-month survival was shown to be improved in those who underwent immediate versus delayed therapy (79\% vs $46 \% ; P=.003)$, and being female was shown to be

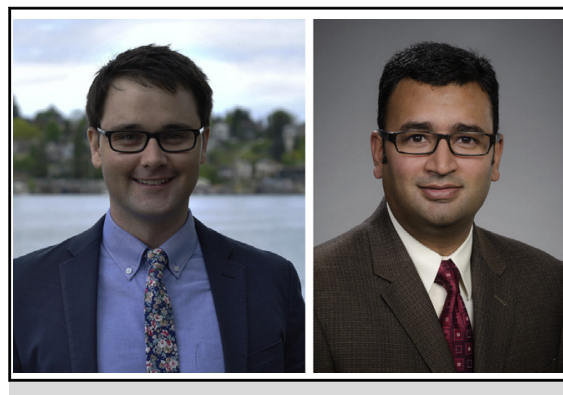

Eric B. Howell, MD, and Nahush A. Mokadam, MD

Central Message

In the management of patients with acute, postcardiotomy right heart failure, we as a field seek to achieve the right timing (early) for intervention as well as the right intensity of support (assist device).

See Article page 1885.

an independent but not statistically significant predictor of mortality. The analysis did not include a comparison of results to patients with RV failure who did not require mechanical support or those who required less-intense support such as intra-aortic balloon pump or prolonged inotropy. The authors conclude that temporary RVAD support continues to be an effective treatment for patients who develop acute RV failure after cardiac surgery, particularly in the setting of left ventricular assist device or cardiac transplantation, with immediate implantation favored over a delayed approach.

With the passage of time comes evolving wisdom, and we believe that this report, which may constitute the largest of its kind, exemplifies the favorable clinical outcomes we would expect from the early initiation of mechanical support in acutely decompensated patient populations. By correcting hemodynamic impairment early with the immediate initiation of mechanical support, the inflammatory cascade and eventual downward spiral that is associated with circulatory collapse is abated, providing the most probable explanation for the improved outcomes observed with early RVAD initiation. As such, this report adds to a growing mountain of evidence suggesting that early initiation of mechanical support for both single-ventricle and biventricular failure is important and is likely the most effective way to influence survival in these particularly fragile patient populations. ${ }^{4,5}$ With regard to the appropriate management of acute, postcardiotomy right heart failure, there is no doubt that we as a field are coming closer to reaching consensus 
of not only achieving the right timing for intervention (early), but perhaps as importantly, the right intensity of support (assist device).

\section{References}

1. Bianucci R, Loynes RD, Sutherland ML, Lallo R, Kay GL, Froesch P, et al. Forensic analysis reveals acute decompensation of chronic heart failure in a 3500-year-old Egyptian dignitary. J Forensic Sci. 2016;61:1378-81.

2. Haddad F, Doyle R, Murphy DJ, Hunt SA. Right ventricular function in cardiovascular disease, part II. Circulation. 2008;117:1717-31.
3. Bhama JK, Bansal U, Winger DG, Teuteberg JJ, Bermudez C, Kormos RL, et al Clinical experience with temporary right ventricular mechanical circulatory support. J Thorac Cardiovasc Surg. 2018;156:1885-91.

4. Bansal U, Jackson K, Winger DG, Teuteberg JJ, Bermudez C, Kormos RL, et al Update on temporary mechanical circulatory support in right ventricular failure [abstract]. J Heart Lung Transplant. 2015;34:S112-3.

5. Fitzpatrick JR, Frederick JR, Hiesinger W, Hsu VM, McCormick RC, Kozin ED, et al. Early, planned institution of biventricular mechanical support results in improved outcomes compared to conversion of a left ventricular assist device to a biventricular assist device. J Thorac Cardiovasc Surg. 2009;137:971-7. 